\title{
Georg Friedrich Meier e os paraísos artificiais de Immanuel Kant ${ }^{1}$
}

\section{Georg Friedrich Meier and "les paradis artificiels" of Immanuel Kant}

\author{
Márcio Suzuki \\ marciosuzuki@usp.br \\ (Universidade de São Paulo, São Paulo, Brasil)
}

\begin{abstract}
Resumo: Este texto procura mostrar como G. F. Meier e Immanuel Kant veem a diversão e a distração como parte essencial do método filosófico.
\end{abstract}

Palavras-chave: G. F. Meier, Kant, meditação, distração.
Abstract: This text aims to show how G. F. Meier and Immanuel Kant see the fun and the distraction as an essential part of the philosophical method.

Keywords: G. F. Meier, Kant, meditation, distraction.

DOI: http://dx.doi.org/10.11606/issn.2318-9800.v19i1p105-116

Para Gisele Batista Candido

Em tempos em que se vê aumentar a voga das biografias, Immanuel Kant permanece provavelmente no imaginário comum como a figura do filósofo sistemático por excelência, que pautava sua vida pela rigorosa pontualidade de seus hábitos. Poucos sabem, porém, que sua vida metódica não foi talvez resultado de uma obsessão neurótica, e que, se não se casou, não foi porque não quisesse, mas porque não ganhava o suficiente para o consórcio, como se exigia na época. A rotina regrada do seu cotidiano seguia uma dietética física e mental baseada nos ensinamentos científicos, médicos, fisiológicos, antropológicos de que se dispunha. Poucos sabem ainda que seu dia a dia era

1. Versão resumida de um texto que faz parte de um estudo sobre "Linguagem e Invenção" na filosofia alemã do século XVIII. 
pontuado por pequenos prazeres saudáveis e inocentes: o filósofo tinha, por exemplo, o hábito de convidar um grupo seleto de amigos para almoçar em casa e de conversar com eles por horas a fio; cultivava o costume das célebres caminhadas ao final da tarde, pelas quais os vizinhos acertavam a hora de seus relógios, e apreciava olhar a paisagem pela janela de seu quarto de estudos. Segundo pessoas do seu círculo, manteve durante mais de cinquenta anos um hábito de fumar cachimbo, prazer a que se entregava várias vezes ao dia, restringindo-o mais tarde, com a saúde já mais debilitada, a uma única cachimbada pela manhã, ao acordar, que acompanhava o frugal desjejum composto somente de uma ou algumas xícaras de chá. Certa vez seu ex-aluno e amigo, o pastor George Michael Sommer, lhe perguntou se ainda mantinha o costume matinal de fumar cachimbo, ao que o filósofo já avançado em anos respondeu:

Sim! Este é um de meus momentos mais felizes. Nele ainda não estou fatigado, eu me recomponho mais e mais, e durante esse tempo também resulta por fim o que e como vou trabalhar ao longo do dia. ${ }^{2}$

A pitada matutina serve para a recomposição do ânimo, como preparativo para o dia que se inicia. Friedrich Theodor Rink, outro ex-aluno e amigo do filósofo, explica melhor o sentido dessa preparação para o dia que virá:

Tal como antes, ele estava de pé às cinco horas da manhã, tomava seu chá e, em seguida, fumava um cachimbo. O tempo que ele empregava para fumar era dedicado à meditação. ${ }^{3}$

Complementando o relato do pastor Sommer, esse depoimento de Rink é interessante por assinalar a relação existente para Kant entre os atos de fumar e de meditar, relação que é um dos modos em que nele aparece o vínculo mais geral entre distração e elaboração conceitual. Sem dúvida, a importância da distração para o trabalho filosófico já havia sido assinalada no século XVIII por David Hume, na conhecida passagem do final do livro I do Tratado da natureza bumana em que, preocu-

2. Citado por Manfred Kühn, cf. KÜHN, M. Kant. Eine Biograpbie. Munique: Dtv, 2003, pp. 454-455.

3. RINK, F. T. Ansicbten aus Immanuel Kant. Königsberg 1805, pp. 82-83. Apud KÜHN, M. Kant. Eine Biograpbie. pp. 258-259. 
pado, entre outras coisas, com os ensinamentos medicinais da época, recomendava o jantar com os amigos, uma partida de gamão como essenciais à saúde do espírito. Mas Kant também conhece a ligação do passatempo com a filosofia a partir de dois autores racionalistas, Johann Georg Sulzer e Georg Friedrich Meier. É este último, principalmente, quem lhe ensina a articulação metodológica entre meditação e distração.

Para Meier é mediante a distração que se pode ajudar a contornar um problema que incomoda todo o racionalismo: como a mente pode suprir sua deficiência em perfazer um cálculo muito complexo, que demanda um tempo muito superior à sua capacidade de prestar e manter atenção, sem se desviar de seu foco de interesse? Como ela é capaz de sustentar sua reflexão por uma série de raciocínio muito longa, se o poder de concentração do espírito humano é limitado? A alma está ligada ao corpo, e é isso que torna difícil a sua capacidade de concentração: uma mosca, um ruído, uma perturbação qualquer pode interromper o desdobramento das ideias, mas querer separar alma e corpo é justamente o caminho a ser evitado. Tanto na meditação filosófica, como na "vida comum", o segredo está em encontrar uma conciliação entre a situação concreta em que indivíduo se encontra e as demandas do espírito. Pensadores abstratos, que não conseguem harmonizar as duas coisas, são geralmente desajeitados, socialmente inábeis; falta-lhe o senso de adequação, ausência que os torna ridículos. Meier dá como exemplo disso um matemático que não sabe se comportar numa reunião social:

Um matemático é convidado para um jantar e se senta à mesa ao lado de uma mulher encantadora. Por infelicidade, um problema algébrico lhe vem à mente. Ele já não vê nem ouve mais nada. Ele come o pão de seus vizinhos. Brindam a sua saúde, ele agradece e tira a peruca. Depois do jantar, lhe servem um cachimbo de tabaco para fumar. Ele pega na mão de sua bela vizinha. Ela se espanta de que um algebrista queira dar uma de galante, mas ela se engana, pois ele usa o seu dedo para encher novamente o cachimbo de tabaco. ${ }^{4}$

Absorto em seu problema algébrico, o matemático age maquinalmente, comicamente, e sua comicidade advém da defasagem entre alma e corpo, entre aquilo que traz no espírito e aquilo que lhe é dado

4. MEIER, G. F. Anfangsgründe aller schönen Wissenschaften, II, p. 86, § 296. 
de concreto. Ele está sonhando acordado, estado que Meier e Kant definirão como uma "distração involuntária": os convivas, a bela mulher a seu lado, o cachimbo que lhe é oferecido pelo anfitrião estão desconectados da série de ideias ou números que o ocupa, exatamente ao contrário do cachimbo de Kant, que é uma forma desejada de prazer, uma "distração voluntária".

A distinção entre distração premeditada, voluntária, e distração impremeditada, involuntária ${ }^{5}$ é fundamental para se entender o jogo de concentração e descontração que compõe o processo meditativo: um dos pontos mais interessantes da escola racionalista em que Kant fez seu aprendizado filosófico é a ideia de que o trabalho de descoberta e invenção conceitual está ligado a um alargamento da mente, a uma expansão em direção à cultura e à sensibilidade unicamente pela qual se torna possível coletar os materiais indispensáveis para a reflexão. Na escola do racionalismo alemão (conhecido também como racionalismo dogmático ou wolffiano-baumgartiano), o trabalho de meditação começa, assim, pelo levantamento e seleção dos conhecimentos que podem ser úteis à investigação. Esse material provém de arquivos localizados na memória, que foram compilados por cada indivíduo ao longo de sua formação cultural, artística, científica, filosófica etc.

Aqui se vê o quanto a escola dogmática está distante da concepção de meditação cartesiana, que é uma introspecção em que se suspende todo o mundo exterior e se faz tabula rasa de todo conhecimento transmitido pela tradição. Para os racionalistas alemães, ao contrário, a cada questão que se investiga, o acervo pessoal de conhecimentos é ativado pela imaginação, que, mediante a associação de ideias, traz à tona tudo aquilo que é pertinente ao assunto sobre o qual se quer meditar. A imaginação está, por isso, a serviço da razão e do entendimento, recuperando na memória os dados de que estes precisam para examinar melhor um problema. Mas a tese racionalista é ainda mais interessante: ao municiar o espírito com ideias próximas ou afinadamente ligadas ao problema, a imaginação permite, ao mesmo tempo, que se examine uma questão ou tema por diferentes perspectivas, mantendo por mais tempo o foco de concentração. É assim que a dis-

5. Sobre ela se pode consultar o parágrafo 47 de KANT, I. Antropologia de um ponto de vista pragmático. Tradução de Clélia A. Martins. São Paulo: Iluminuras, 2006. 
persão por representações próximas ao tema central é essencial à concentração. O procedimento é o inverso do ensinado por Descartes, que preconizava a concentração num foco só, numa ideia clara e distinta, concentração, porém, difícil de manter por muito tempo e só alcançada em ocasiões excepcionais (com um quarto bem aquecido, um robe de chambre...). Ao contrário do que faz a meditação cartesiana, a regra dogmática de "variação eidética" (para brincar com a terminologia husserliana) afirma que muitas ideias apenas claras são geralmente mais fecundas do que uma única ideia clara e distinta e, além disso, ajudam a fixar por mais tempo a concentração sobre o tema em questão. Ou seja, ao contrário do que se acredita, o alargamento, a expansão, a "dispersão" por um número maior de ideias afins ajuda a manter o foco. Meier conclui, assim, que o número de ideias novas encontradas pela imaginação é indispensável a "investigações filosóficas profundas". Isso também ocorre porque, ao percorrer o repertório dos tópicos ligados à questão, a imaginação encontra as palavras, as imagens sem as quais o intelecto pensaria no vazio, em "abstrato". A imaginação é o ponto de apoio da reflexão, porque também fornece à linguagem os sinais ou imagens de que esta precisa para se manter mais tempo "focada". A analogia com o cálculo matemático ajuda a compreender melhor esse ponto: como ensina a álgebra dos modernos, operações muito complexas não podem ser realizadas "de cabeça", sem sinais ou imagens que representem e simplifiquem quantidades muito grandes. ${ }^{6}$

A concentração necessária à meditação filosófica supõe, portanto, um jogo entre duas formas de atenção, voluntária e involuntária, que corresponderá a modos diferentes de operar da imaginação: esta procede associativamente, quer ligada a uma representação externa, quer ligada a uma representação interna, podendo ser também involuntária ou voluntária. Neste caso, ela obedece a um fim estipulado pelo entendimento: ao se propor um tema, a mente põe imediatamente a imaginação associativa a trabalhar no sentido de buscar tudo aquilo que se relaciona àquele tema, inclusive no que se refere à terminologia, mas esse trabalho pode ser perturbado, caso a imaginação

6. A ligação da imaginação com a "coleta" dos materiais necessários e do vocabulário próprio ao tema pode ser vista no texto 1 abaixo, em que Kant ensina seus alunos como elaborar a redação sobre algum tema, por exemplo, uma oração fúnebre. 
involuntária "externa", ligada ao corpo, seja afetada por alguma percepção que não tenha que ver com o assunto tratado. Há pessoas que precisam de isolamento para se concentrar, cuja imaginação é frequentemente levada, pela menor associação externa, a um "lugar" bem distante daquele que as ocupa em espírito. Existem outros indivíduos, no entanto, que podem trabalhar num quarto que dê para uma rua barulhenta, que não se incomodam com o entra e sai da mulher, dos filhos e dos criados. Diferentemente do que ocorre com os primeiros, o que se alcança aqui é uma efetiva harmonia, no sentido leibniziano, entre natureza e espírito, um convívio fecundo entre as ideias evocadas internamente pela imaginação e as circunstâncias "perturbadoras" da realidade concreta. $\mathrm{Na}$ verdade, estas, se bem assimiladas, mais ajudam do que prejudicam a reflexão.

Segundo Meier, haveria dois modos de proceder a essa conciliação entre a imaginação interior e a sensações externas: as sensações concretas podem ser utilizadas como impulso à imaginação interna, quando aquelas são favoráveis a esta; ou se pode tentar gerar sensações artificiais que correspondam às representações imaginárias. Ou seja, se as impressões presentes são conflitantes com aquilo de que a imaginação voluntária deve trazer para a meditação, então é preciso ir em busca de impressões produzidas artificialmente que correspondam a essa necessidade. Esse truque, que consiste em simular sensações afinadas com as representações imaginárias, deve ser aprendido com os poetas, que, em busca de inspiração, vão dar um passeio, se embriagam ou encontram um outro modo qualquer de se "entusiasmar", isto é, de atingir a inspiração poética. O objetivo é fazer com que o que é vivido concretamente se compatibilize com as representações imaginárias, e todo interesse está em observar como a meditação filosófica é de certo modo concebida, não só em Meier como também em Kant, por analogia com os estados de "êxtase" dos poetas, embora certamente numa medida bem mais moderada, inocente, saudável do que aqueles "paraísos artificiais" descritos por Baudelaire. ${ }^{7}$

Que Kant conhecia bem essas técnicas, truques ou artifícios de conciliação das duas imaginações, a voluntária e a involuntária, fica evidente por alguns exemplos.

O primeiro é extraído de uma anedota do Spectator, de Addison e Steele. Um advogado, excelente orador, costumava trazer uma linha

7. Cf. o texto 2 abaixo, de Georg Friedrich Meier. 
de costura para as suas defesas no tribunal, linha que enrolava e desenrolava, incessantemente, à medida que seu discurso avançava. Certo dia, um adversário astuto lhe subtrai da bolsa a linha de costura, e o advogado se vê em apuros, perdendo "o fio do discurso". A explicação de Kant é a seguinte: a linha de costura servia para que a imaginação involuntária externa do advogado não fosse atraída por nada que ocorresse no tribunal, enquanto sua imaginação voluntária interna estava livre para fornecer as ideias, imagens e palavras de que precisava para seu discurso.

Segundo exemplo: quando alguém vê uma pessoa, geralmente a figura dessa pessoa deve ser representada por inteiro, pois se há algo nela que chama particularmente a atenção, por exemplo, a falta de um dente, "a mente sempre adere a esse lugar chamativo" e a partir daí a imaginação segue um curso ingovernável.

Terceiro exemplo: num dos cursos ministrados por Kant havia nas primeiras fileiras um aluno que vestia um casaco faltando um botão. Toda vez que o olhar recaía sobre ele, o professor se desconsertava e não conseguia achar o fio da meada. O que ocorre é bastante simples, explica Kant: se a imaginação se fixa em algo que não diz respeito ao tema, ela se desvia, causando distração. E a melhor estratégia para evitar essa distração involuntária não é, diferente do que pensavam os filósofos, o esforço de abstração, porque abstrair é um esforço inatural e demanda mais energia do que prestar atenção. A melhor maneira de evitar a distração involuntária é tapeá-la com outra distração, agora voluntária e metódica, como a linha de costura empregada pelo advogado referido no Spectator.

Esses exemplos ajudam a compreender como funciona a relação entre fumar cachimbo e meditar para Kant. $\mathrm{O}$ ato de fumar é uma das maneiras de distrair a imaginação "externa", fazendo-a colaborar com a imaginação "interna". O que ocorre com o fumo se explica da mesma maneira que o estado da mente provocado pelos movimentos das águas de um riacho ou das ondas do mar por entre rochas, diante de paisagens muito amplas, ou quando se está num aposento com uma lareira etc.: em todos esses casos, o "transcurso da fantasia" é entretido indefinidamente pelas sensações, porque, no jogo incessante das formas, ela não se detém numa figura determinada e fixa. As imagens do riacho, do mar, da paisagem, da lareira, são vagas, isto é, não direcionam a imaginação externa para um objeto fixo, o que impediria a imaginação interna de flutuar em liberdade. É por isso que só se tira proveito se- 
melhante do cachimbo fumando num lugar iluminado, pois só aí se pode acompanhar o rodopio indefinido da fumaça pelo ar: o tabaco, diz o filósofo, "ocupa nossa imaginação com as diferentes figuras que o fumo vai assumindo. Por isso, o tabaco não tem tanto gosto no escuro..." ${ }^{8} \mathrm{O}$ jogo das formas que a fumaça vai tomando, sem ter uma figura definida e definitiva, produz uma distração dos sentidos externos, favorecendo o jogo interior da mente com os objetos que a ocupam. Mecanismo semelhante explicará o juízo estético, como jogo de belas formas que promove a vivificação das faculdades da mente, e essa proximidade do prazer estético, explicitado na Terceira Crítica, com a meditação filosófica não é acidental. Fica, porém, para outro lugar tentar deslindar melhor o nexo entre meditação e reflexão.

Assim como as "distrações" que acabam de ser mencionadas, a música também provoca efeito semelhante, pois ela

pode colocar um poeta ou um filósofo, se não a ouve como entendido, numa disposição na qual pode apreender ou mesmo ter em seu poder ideias sobre os objetos de sua ocupação ou dileção que não teria captado com tanto êxito se tivesse se fechado sozinho em seu aposento. ${ }^{9}$

Como o fumo, a música - se não é ouvida com ouvidos de especialista - pode colocar o poeta ou filósofo numa disposição de espírito favorável à descoberta de ideias em suas respectivas ocupações, muito mais do que se tivessem se retirado a seu quarto de estudos. O que geralmente se afirma sobre o desprazer de Kant com a música, diz respeito à música enquanto forma de distração involuntária, que interfere no curso do raciocínio. Como forma de distração voluntária, a música permite à imaginação vaguear pelos labirintos internos, a fim de que ali o entendimento encontre palavras adequadas ao discurso e imagens justas para a elaboração poética ou conceitual. Tanto a redação de um texto quanto a meditação (as operações se confundem) se fazem em princípio de modo caótico, um pouco à aventura - "tumultuariamente", como afirma Kant. ${ }^{10}$ É por isso que as regras lógicas que ele apresenta para o ato de meditar (isto é, os preparativos para a exposição de uma questão segundo um método) são análogas àquelas

8. KANT, I. Antropologia, p. 72.

9. Idem, ibidem.

10. Cf. Texto número 3 abaixo. 
que apresenta para a redação de um texto. ${ }^{11}$ Em suma, a meditação está ligada ao exercício da linguagem, o que assinala, mais uma vez, a afinidade do filósofo com o poeta. ${ }^{12}$

$\mathrm{Na}$ meditação filosófica, como na composição de um escrito, a ampliação do conhecimento produzida pela distração voluntária é indispensável à concentração. Ouvir música, frequentar a sociedade, fumar são bem mais benéficos ao trabalho conceitual do que ensimesmar-se.

No conhecido poema "Tabacaria", falando do mesmo prazer de fumar, o engenheiro Álvaro de Campos seguiu aparentemente o caminho inverso ao de Kant:

Acendo um cigarro ao pensar em escrevê-los

E saboreio no cigarro a libertação de todos os pensamentos.

Sigo o fumo como uma rota própria,

E gozo, num momento sensitivo e competente,

A libertação de todas as especulações

E a consciência de que a metafísica é uma consequência de estar mal disposto.

Não deixa, porém, de ser curioso que tanto o poeta quanto o filósofo tenham visto que a possibilidade ou impossibilidade da metafísica passe pelo prazer de fumar, pelos rodopios errantes produzidos pela fumaça do tabaco.

\section{Textos $^{13}$}

\section{$A$ imaginação de Meier e Kant}

Texto 1: Menschenkunde, de Immanuel Kant ${ }^{14}$

Jogamos com as imagens de nossa imaginação; na imaginação involuntária, porém, é a ficção involuntária que joga conosco. A ima-

11. Ver texto 1 abaixo, já referido.

12. Cf. novamente o texto 3 abaixo.

13. Os textos aqui traduzidos têm relação com uma passagem da Antropologia Braner, referida e analisada por Ricardo Ribeiro Terra em TERRA, R. Reflexão e sistema: a propósito da Primeira introdução e da gênese da Crítica do Juízo. In: Passagens. Estudos sobre a filosofia de Kant. Rio de Janeiro: UFRJ, 2003, p. 28.

14. KANT, I. Vorlesungen über Antbropologie. In: Kant's gesammelte Schriften. Berlim: de Gruyter, 1997, p. 946. 
ginação voluntária é geradora, mas a fantasia delira, e significa o curso involuntário de nossas imaginações, em que estas não se apresentam segundo escolha e desígnio, nem podem ser conduzidas e regidas como bem nos aprouver, mas surgem na mente por um ensejo casual, tomando então, porém, um curso na alma segundo leis, sem que possamos pensá-lo com precisão. Fantasista é o homem que não pode proceder a mudanças no curso de seus pensamentos como bem queira. É digno de nota que primeiro podemos dirigir, de maneira voluntária, nossa imaginação a um objeto, mas esta prossegue por si mesma o seu jogo, e já não seguimos mais voluntariamente, mas é uma força interna da alma que nos conduz, as imagens tomam um andamento próprio, e não sabemos como chegamos a elas; foi o que se passou com muitas invenções. Quero refletir sobre algo; seleciono primeiro todo tipo de representações secundárias que estejam em vínculo com minha representação principal. Por exemplo, quem faz estudos para uma oração fúnebre, tem de ter em si mesmo na própria mente a perspectiva de um futuro ou de uma colheita promissora, ou a morte como fim de todas as misérias. Ele toma então um único desses objetos, ao que a imaginação o leva deste único a uma profusão de outros pontos; a fantasia segue em seu andamento, dá com imagens que têm seu nexo, mas que vão pouco a pouco levando a imagens menos conexas entre si, até que por fim o entendimento ordena tudo de novo. Essa lei pela qual o entendimento ordena tudo se chama lei da associação (lei de agrupamento). Representações são associadas, se há um fundamento de ligação por meio do qual as ideias são aparentadas ou, pelo menos, vizinhas, de modo que se possa vinculá-las mediante a unidade do espaço ou do tempo.

Texto 2: Anfangsgründe aller scbönen Wissenscbaften (Princípios de todas as belas artes), de Georg Friedrich Meier ${ }^{15}$

Temos de evitar que as representações imaginárias sejam contrárias às sensações, e isso ocorre sempre que a imaginação nos represente algo que não tenha nenhuma afinidade com as sensações atuais. Esse conflito é bem prejudicial às representações imaginárias, pois então elas são obscurecidas e abafadas pelas sensações que lhes contradizem. Ou, caso devam triunfar, as representações imaginárias

15. MEIER, G. F. Anfangsgründe aller schönen Wissenschaften. Halle: Hemmerde, 1749. Reprodução facsimilar: philosophiebuch.de, 2003-2006, § 384 . 
provocam muitos erros ridículos, como a distração e a ausência de espírito. Se quisermos, pois, ter uma boa evolução no aprimoramento da imaginação, temos de fazer as representações imaginárias concordar com as sensações simultaneamente atuais. Essa concordância será alcançada, em parte, se direcionamos nossa imaginação para objetos aparentados com as sensações atuais; em parte, se produzimos sensações que são aparentadas com aquelas representações imaginárias que desejamos ter. Esse artifício é usado pelos poetas, que vão passear, que se embriagam ou que encontram alguma maneira de se entusiasmar. Pois as sensações que daí recebem são bastante semelhantes às imagens vivas de sua imaginação que querem despertar.

Texto 3: Logik Pbilippi, de Immanuel Kant ${ }^{16}$

No início meditamos tumultuariamente. Temos de anotar aquilo que nos ocorre quando de tempos em tempos nos passam pela cabeça pensamentos que não tivemos na vida. Primeiro escrevemos todos os pensamentos, como os temos, sem ordem. Depois começamos a ordenar e então a subordinar. Se queremos compor algo, precisamos certamente ter pronto em geral o esqueleto do sistema e, então, a divisão em capítulos.

Assim, em toda composição, precisamos executar três trabalhos[:]

1. Escrever todos os pensamentos sem ordem.

2. Fazer um plano geral.

3. Elaborar as partes.

Com respeito especificamente à meditação, é preciso certamente ser por natureza inclinado a ela; mas podemos nos iniciar nela quando, apresentando-se-nos as palavras, nos exercitamos em representar as coisas na imaginação; quando, por assim dizer, nos tornamos internamente conscientes das palavras, o que elas significam, e prestamos atenção àquilo que se passa em nós.

\section{Referências}

KANT, I. Antropologia de um ponto de vista pragmático. Tradução de Clélia A. Martins, São Paulo: Iluminuras, 2006.

16. KANT, I. Vorlesungen über Logik I. In: Kant's gesammelte Scbriften. Berlim: de Gruyter, 1966, p. 484. 


\section{Márcio Suzuki}

Vorlesungen über Antbropologie. In:

Kant's gesammelte Schriften.

Berlim: de Gruyter, 1997.

Vorlesungen über Logik. In:

Kant's gesammelte Schriften. Berlim: de

Gruyter, 1966.

KÜHN, M. Kant. Eine Biograpbie, Munique: Dtv, 2003.

MEIER, G. F. Anfangsgründe aller schönen Wissenschaften. Halle: Hemmerde, 1749. Reprodução facsimilar: philosophiebuch.de, 2003-2006.

TERRA, R. R. Reflexão e sistema: a propósito da Primeira introdução e da gênese da Crítica do Juízo. In: Passagens. Estudos sobre a filosofia de Kant. Rio de Janeiro: UFRJ, 2003.

Recebido em 26.03.2014

Aceito em 06.06.2014 